\title{
Chapter 12 \\ Building Resilience in Humanitarian \\ Hospital Programs During Protracted \\ Conflicts: Opportunities and Limitations
}

\author{
Ingrid Tjoflåt and Britt Sæetre Hansen
}

\begin{abstract}
Humanitarian hospital programs supporting health systems during protracted conflicts require a combination of short- and long- term approach. Working in partnership, sharing of knowledge, provision of drugs, equipment and human resources together with a multi-sector and multilevel approach could contribute to build resilience in humanitarian hospital programs during protracted conflicts. However, withdrawal of humanitarian support after two years could lead to a possible decline in the quality of care linked to the end of the delivery of drugs, equipment and human resources if the local and national health authorities are not able to find any solutions to the chronic vulnerability. Continuous conflicts may continue to cause new challenges in these hospitals.
\end{abstract}

Keywords Humanitarian $\cdot$ Hospital programs $\cdot$ Protracted conflicts

\subsection{Introduction}

Protracted conflicts or recurring long-lasting conflicts based on one main conflict or from many different chronic conflicts gradually destroy infrastructure, services and living conditions. Not only a cause of human suffering, they are reasons for long-term displacement, migration and development delays. The character of these conflicts generates extreme fragility in basic services as well as in social, economic and environmental systems. The health systems in these conflicts are often overwhelmed as health professionals flee, infrastructure is destroyed and the provision of drugs and medical supplies is stopped [1]. Under these conditions, there are long-term humanitarian needs in terms of law and order, water, electricity, food security, health care and education. Humanitarian aid that supports health care in these conflicts requires a combination of short- and long-term approaches.

I. Tjoflåt $(\varangle) \cdot$ B. S. Hansen

Faculty of Health Sciences, University of Stavanger, Stavanger, Norway

e-mail: ingrid.tjoflat@uis.no 
Building resilience has been raised as a new organizational principle by the United Nations, donors and Non-Governmental Organizations in development, climate change adaption and humanitarian aid [2, 3]. The key in building resilience is an attempt to reduce the dramatic decline in development and prevent unacceptable levels of human suffering that crisis and conflicts can cause [2, 4, 5]. However, it has been reported that it is not clear how resilience should be promoted during and after conflicts [6]. Frankenberger et al. [7] state that building resilience may be impossible where governments are fragile and where there are ongoing conflicts. The basic minimum conditions have to be present first. Nevertheless, it has been described that the humanitarian approach has to work with two perspectives simultaneously, that is, responding to immediate needs and mitigating the cumulative impact. The longer the conflict lasts, the more necessary it becomes to engage with people and communities at a structural level. Working in partnership is therefore an essential attribute in building resilience in humanitarian programs. Partnership reflects a participatory attitude built upon sensitivity, shared understanding and local knowledge [3, 8, 9]. There is always capacity in people or communities: to strengthen resilience is to increase this capacity. Coping and adapting are central aspects of resilience, and they refer to different actions that people do to mitigate difficulties or suffering. When resilience is understood as a capacity, it means that it is not a fixed concept but a dynamic one that varies and can change continuously. Consequently, it is then more relevant for humanitarian programs during protracted conflicts to focus on "building resilience" as a process that remains dynamic rather than trying to define and measure "resilience" as an outcome of an intervention [10].

There are numerous case examples from disaster areas and other situations of conflicts that describe the development and strengthening of national and local resilience capacities $[11,12]$. As far as can be seen from the literature, there are no descriptions addressing the resilience in humanitarian hospital programs that improve the quality of care in local hospitals during protracted conflicts.

Therefore, this chapter is intended to shed light on the opportunities and the limitations of building resilience to improve the quality of care in local hospitals by implementing humanitarian hospital programs during protracted conflicts. Common areas of challenges in local hospitals during protracted conflicts will be described. Building resilience in the local hospital will then be discussed in relation to partnership, sharing of knowledge and provision of drugs, equipment and human resources.

\subsection{Experiences from the Field}

The first author has extensive experience working to improve the quality of care in local hospitals with a humanitarian organization in different protracted conflicts in Africa, Asia and the Middle East. Moreover, she has conducted qualitative research related to challenges in improving the quality of care in different humanitarian programs [13-15]. Based on the first author's experience, challenges local health personnel face working in hospitals during protracted conflicts are described. To emphasize 
the challenges and highlight important elements, the listed challenges have been simplified. Of note, the challenges does not refer to any specific hospital, but has been constructed from a range of experiences.

Common areas of challenges in local hospitals during protracted conflicts

- There are very few beds compared to the population.

- The wards are normally overcrowded and the mortality rate is high. Due to ongoing conflicts, patients often cause extra caseloads in the wards.

- There is an insufficient supply of drugs and disposable equipment to treat the patients. The patients and their relatives have to purchase drugs and equipment in the local pharmacy, which often delays treatment and results in poor quality of care. To reduce the patients' financial costs, the staff have to use as little equipment as possible when performing procedures.

- There is a lack of basic medical equipment, such as a blood pressure cuff, stethoscopes, oxygen and mattresses. Some of the equipment is broken. Even if some health personnel wanted to try to maintain the national standard of care, the lack of drugs, disposable equipment and medical equipment makes it impossible.

- Sometimes the hospital has problem with insufficient electricity and water.

- Maintenance of the hospital buildings has not been carried out for years.

- There is a lack of skilled staff because a majority has fled the country. In addition, due to the ongoing conflict there is not enough health staff educated.

\section{Support by an international humanitarian organization}

Sometimes humanitarian organizations provide support to one ward, for example to a surgical ward due to the extra pressure war and violence put on surgical services. Such support might include teaching/supervision and logistical support related to essential medical drugs and equipment with the aim of building resilience by improving the quality of care. Some maintenance support of the ward may also be carried out. Such support might be offered as a two-year partnership project. The general objective in such projects, based on a joint assessment by the hospital leadership and the humanitarian organization, might be that surgical patients will be cared for in a functional, well-equipped and maintained department with skilled health personnel who meet the relevant national standards of care. The international humanitarian organizations may send visiting specialist health workers, who might do short mission in the hospital and conduct training. The visiting health workers from the humanitarian organization may work alongside the local health staff to share knowledge to achieve a sustainable standard of treatment and care, comparable with the national standards in the country. In addition, the humanitarian organization may provide a program manager and one administrator to work with the management in the hospital for the length of the project. 


\subsection{Discussion}

Based on the challenges listed above, three essential areas for building resilience in the local hospital surgical ward will be discussed. These are partnership, knowledge sharing and the provision of drugs, equipment and human resources. The discussion will focus on both the opportunities and the limitations in building resilience.

\subsubsection{Partnership}

One opportunity for building resilience is that the project is a partnership project. Not only is working in a partnership an essential attribute in building resilience in humanitarian programs, but it also reflects a participatory attitude [3, 8, 9]. The general objective of humanitarian projects are based on a joint assessment by the hospital leadership and the humanitarian organization. Jointly assessing and defining the general objective of a project together can provide opportunities for building resilience through a dialogue encompassing mutual respect and a willingness to listen and understand the local hospital's point of view [3, 8, 9].

However, a partnership project also requires a proper understanding of how the hospital system works and a deeper engagement with the structures in the hospital as well as with the health system in the country $[1,16]$. Therefore, to build resilience in one ward or in a small part of a hospital, the humanitarian organization has to conduct a robust analysis that goes beyond needs assessments [12]. Moreover, the visiting health workers, the program manager and administrator from the humanitarian organization should listen to the local health workers and understand their perspectives as well as those of the hospital and the health system. One limitation in building resilience in such partnership projects is that the humanitarian support only focus on a small part of a hospital.

Forming a successful partnership takes time and expertise. Whether the humanitarian organization has the time and the knowledge to build a partnership is a question that must be asked. Based on the first author's experiences, it can be challenging to create a good partnership in areas of conflict due to security constraints, the immediate need to save lives, the limited time available to set up a program and/or a fragile and/or absent local management and authorities. These experiences are also reported in studies. A study that interviewed more than 6,000 people from around the world who have received international assistance showed that, all too often, trust and respect between partners can diminish during emergencies. The study reported that the local partners perceived the international agencies to be "paternalistic" in taking over local initiatives. Additionally, a lack of respect for and appreciation of local knowledge and contributions limited the extent of the partnerships, since the locals are rarely involved in the decision-making processes with their partners [17]. 


\subsubsection{Knowledge Sharing}

Another opportunity in the project for building resilience with regard to improving the quality of care is the sharing of knowledge and experience between the visiting health workers and the local staff in the surgical hospital ward.

To share knowledge, the visiting health workers must recognize and appreciate the efforts the health personnel working in the ward who have done what they could to maintain the quality of care during years of conflict. The described challenges reveals that, due to a lack of equipment, the staff had to find solutions to take care of patients compromising daily the national standard of care and treatment. The visiting health workers, who work alongside the local health staff in the surgical ward, should be able to identify and understand the local staff's efforts in trying to maintain standards of care and the visiting health workers should value the local knowledge and experience. The plans and efforts should be put at the service of the local health staff's initiatives and their capacities. This is emphasized in the literature and it serves to establish humanitarian policy documents as essential attributes for building resilience $[3,8$, 9]. However, studies from humanitarian missions to conflict areas show that visiting health workers rarely acknowledge or use the local knowledge $[15,18,19]$. Tjoflåt et al. [15] reported that the visiting nurses admired the local nurses' creativity in work situations with few available resources. However, it was a challenge for the visiting nurses to utilize this knowledge when they worked together with local nurses in the ward to improve the quality of care. The visiting nurses had problems adhering to the local nursing standards, which they saw as substandard compared with their home country, and they took care of the patients themselves (ibid). The visiting nurses' negative attitude towards local standards and taking care of the patients themselves could possibly hamper the improvement of care in the surgical ward and further limit the building of resilience.

Without improving the availability of drugs and medical equipment and reversing the shortage of health personnel in the ward, knowledge sharing could have only a minimal impact on the quality of care for surgical patients.

\subsubsection{Provision of Drugs, Equipment and Human Resources}

Other opportunities for building resilience in the hospital's surgical ward come from the provision of essential drugs and equipment to the surgical ward for the length of the project. Moreover, the maintenance to the ward. Such support will certainly improve the quality of care and will provide opportunities for building resilience, but it does not solve the chronic vulnerability related to supply, which often is linked to ongoing conflicts.

Another limitation for building resilience may be the lack of human resources. The lack of qualified staff may be one reason for high mortality rate in these hospitals. For the length of the project, the visiting health workers will provide some extra health 
staff to the ward when they work alongside the local staff to share knowledge, but the quality of care may decline when the project ends if the national health authorities fail to increase the number of staff permanently.

Building resilience in these areas requires a multi-sector and multilevel approach. Different types of interventions and sequentially have to be addressed with various department in the hospital as well as with the management of the hospital to enable resilience related to provision of drugs, equipment and human resources. The lack of supply and human resources in the hospital can be reported to the national health authorities by the management of the hospital with the support of the international humanitarian organization, but the national authorities have to find long-term solutions to ensure sufficient supplies and human resources. The European Commission's Action Plan for Resilience in Crisis Prone Countries 2013-2020 reports that building resilience is a long-term process and should be embedded in national policies and planning. Where the state and situation are fragile, it is essential to identify functioning systems within local institutions and support their capacity.

Another limitation in the humanitarian support for building resilience is the length of the project. Closure of the partnership project after two years and ending the provision of essential drugs, equipment and the human resource support to the surgical ward may result in a decline in the quality of care if no other solutions are found for example an extension of the project. To build resilience often requires a long-term engagement and investment [4].

\subsection{Conclusion}

The discussion of the experienced challenges revealed that partnership, knowledge sharing, the provision of drugs, equipment and human resources together with a multisector and multilevel approach could contribute to build resilience in humanitarian hospital programs during protracted conflicts. However, withdrawal of humanitarian support after two years could lead to a possible decline in the quality of care linked to the end of the delivery of drugs, equipment and human resources if the local and national health authorities are not able to find any solutions to the chronic vulnerability. On the other hand, limiting the support to single wards or smaller part of local hospitals during protracted conflicts may partial support the hospitals' resilience. Continuous conflicts may continue to cause new challenges in these hospitals. Realistically it will not be possible for a humanitarian organization to support all challenges in local hospitals during protracted conflicts. Priorities must be determined according to the context and resources available. 


\section{References}

1. ICRC, Protracted conflict and humanitarian action: some recent ICRC experiences. Technical report (International Committee of the Red Cross, 2016)

2. Action plan for resilience in crisis prone countries 2013-2020, Commission staff working document, European Commission (2013)

3. UN, The Sendai framework for disaster risk reduction 2015-2030. Technical report (United Nations, 2015)

4. IFRC, The road to resilience: bridging relief and development for a more sustainable future. Technical Report (International Federation of Red Cross and Red Crescent Societies, 2012). IFRC discussion paper on resilience

5. S. Levine, I. Mosel, Supporting resilience in difficult places: a critical look at applying the "resilience" concept in countries where crises are the norm. Technical report (Humanitarian Policy group, Overseas Development Institute, 2014)

6. S. Levine, A. Pain, S. Bailey, L. Fan, The relevance of "resilience"? HPG Policy Brief, vol. 49 (Humanitarian Policy Group, 2012)

7. T. Frankenberger, T. Spangler, S. Nelson, M. Langworthy, Enhancing resilience to food insecurity amid protracted crisis (2012)

8. C. Byrne (ed.), Participation crisis-affected populations in humanitarian action: a handbook for practitioners overseas (Overseas Development Institute, 2003). The Active Learning Network for Accountability and Performance in Humanitarian Action (ALNAP)

9. GPH, The global humanitarian platform's principles of partnership (2007)

10. S.B. Manyena, The concept of resilience revisited. Disasters 30(4), 434-450 (2006)

11. EU resilience compendium saving lives and livelihood. Technical report, European Commission Humanitarian Aid and Civil, Protection DG (2015)

12. IFRC, World disaster report (2016) Resilience: saving lives today, investing for tomorrow. Technical report (International Federation of Red Cross and Red Crescent Societies, 2016)

13. I. Tjoflåt, B. Karlsen, Challenges in sharing knowledge: reflections from the perspective of an expatriate nurse working in a South Sudanese hospital. Int. Nurs. Rev. 59(4), 489-493 (2012)

14. I. Tjoflåt, B. Karlsen, Building clinical practice in the Palestine Red Crescent operation theaters in Lebanon: reflections from the perspective of an expatriate nurse. Int. Nurs. Rev. 60(4), 545549 (2013)

15. I. Tjoflåt, B. Karlsen, S.B. Hansen, Working with local nurses in order to promote hospitalnursing care during humanitarian assignments overseas: experiences from the perspectives of nurses. Jn. Clin. Nurs. 25, 1654-1662 (2016)

16. E. Hollnagel, Making health care resilient: from safety -1 to safety -ii, in Resilient Health Care, ed. by E. Hollnagel, J. Braithwaite, R.L. Wears (Ashgate, Farnham, 2013)

17. M.B. Anderson, D. Brown, I. Jean, Time to listen: hearing people on the receiving end of international aid. CDA Collaborative Learning Projects (2012)

18. M. Girgis, The capacity-building paradox: using friendship to build capacity in the South. Dev. Pract. 17(3), 353-366 (2007)

19. A.L. Martiniuk, M. Manouchehrian, J.A. Negin, A.B. Zwi, Brain gains: a literature review of medical missions to low and middle - income countries. BMC Heal. Serv. Res. 12(134) (2012) 
Open Access This chapter is licensed under the terms of the Creative Commons Attribution 4.0 International License (http://creativecommons.org/licenses/by/4.0/), which permits use, sharing, adaptation, distribution and reproduction in any medium or format, as long as you give appropriate credit to the original author(s) and the source, provide a link to the Creative Commons license and indicate if changes were made.

The images or other third party material in this chapter are included in the chapter's Creative Commons license, unless indicated otherwise in a credit line to the material. If material is not included in the chapter's Creative Commons license and your intended use is not permitted by statutory regulation or exceeds the permitted use, you will need to obtain permission directly from the copyright holder.

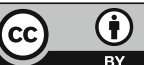

